\title{
Mobile gaming: Industry challenges and policy implications
}

\author{
Claudio Feijoo , José-Luis Gómez-Barroso , Juan-Miguel Aguado , Sergio Ramos
}

\begin{abstract}
A B S T R A C T
Mobile games are a prime example of a successful mobile application and demonstrate the increasing range of platforms for the media and entertainment industries. Against this convergent background, this paper introduces the basic features of the mobile gaming market and its industrial ecosystem together with its main actors and activities. The focus of the paper lies in the challenges ahead for the evolution of mobile applications into a potentially dominant game platform and the possible disruptions along this road. The deep personal relationships between users and their mobile devices are considered to further explore the link between mobile games, players' strategies and pending techno-economic developments. The paper concludes with a brief discussion of some policy options to assist with the development of this domain.
\end{abstract}

\section{Introduction}

Applications for mobile devices are an outstanding example of the convergence between electronic communications and the media and entertainment industries. Convergence usually implies major expectations of new businesses based on the opportunities of an unexplored domain as well as the practical difficulties in transforming existing markets and understanding new preferences of users. This is the case for mobile gaming. In fact, the appeal and opportunities of this market are attracting innovators, entrepreneurs and many old and new industry players. Together, these groups are reshaping this industry.

There has also been some academic interest in the field of mobile gaming (or, more appropriately, in mobile entertainment) during the last decade. However, the available literature has adopted either the social media perspective or the game design perspective. A holistic view is still lacking, specifically in view of the recent developments in mobile gaming. There is very recent academic interest in mobile platforms, in the development of mobile applications on these platforms, and in the videogame industry in general. References provided throughout the text present some of the most relevant contributions with regard to mobile gaming. However, the authors consider the specific mobile gaming perspective to be insufficiently addressed thus far.

This paper provides an overview of the status and future prospects of mobile gaming, with a view toward possible policy options that may target this area. Its main aim is to provide some direction for further academic research on this timely topic. The methodology used in this study is based on desk research of the available literature and the data provided by the industry, complemented by a small survey conducted in 2010 to verify the status of the domain from the users' perspective. 
The paper is structured as follows. After a brief summary of the evolution of the mobile gaming industry, the mobile game ecosystem will be introduced in some detail, along with the main players' strategies and techno-economic models as an indication of the status of the supply side. The demand side is presented in the next section. Section 5 presents the challenges ahead for the evolution of mobile devices into a potentially dominant game platform as well as some of the possible disruptions along this road. Finally, some policy options are discussed to conclude the paper.

\section{Background: the evolution of mobile gaming}

\subsection{Mobile gaming in the era of feature phones}

When mobile phones were just phones, users played simple games that were embedded in their handsets. The true mobile gaming market became international around 2002, ${ }^{1}$ when operators began commercialising phones that were capable of downloading games from their own portals, ${ }^{2}$ and a separate spending stream was generated. Until 2007, the market was characterised by relatively simple games that were similar to those developed for consoles 10-15 years earlier. The complexity of the games was fundamentally restricted due to the limited graphical and processing power capabilities of the handsets. The games were typically downloaded from the operator's portal or third-party stores after the user paid a onetime fee via a premium SMS (Goggin \& Spurgeon, 2007). Alternatively, for some models of mobile devices, games could be downloaded from a third-party website to a PC and then side-loaded. However, the majority of users played the games embedded in the handset only. Thus, the most popular mobile games during this period were single-player board games, word games and puzzles of different types, with Tetris as a main example. Because of the simplicity of the games and the limitations of the phones, the average amount of time spent playing on the mobile phone was limited to approximately $30 \mathrm{~min}$ (PWC, 2009), which was rather different from the hours that are typically required to complete a console game. Furthermore, the mode of playing was mostly casual, while filling time between daily activities. This casual gaming style had the positive effect of widening the demographics of players, with the important consequence of including women as regular gamers.

The main techno-economic model at the time was a vertical integration, with the mobile operator taking centre stage. This is the notorious walled garden model. ${ }^{3}$ Within it, mobile games were provided through the mobile operator's portal, and they functioned on a particular set of handsets that were marketed and subsidised with the deliberate participation of the mobile operator. The revenues were generated by operators within their own value structure. For game developers, the walled garden approach meant that their mobile offerings had to be technically and business compatible or even developed within a specific mobile carrier platform. Each operator used a different platform, so developers faced significant opportunity costs. Furthermore, because operators typically dealt only with established brands, the process for participating in an operator's system was often time consuming and expensive for start-ups, if they succeeded at all. In addition, a number of exclusive deals were in place that precluded open agreements with game developers or publishers.

\subsection{Mobile gaming in the era of smartphones}

Mobile gaming possibilities changed in 2006-2007 with the introduction of the first wave of smartphones and the availability of broadband connections with flat data fees.

Nokia had been the prime mover, with its failed attempt to create both a popular mobile phone and a handheld console, the $\mathrm{N}$-Gage, as early as 2003. Acknowledging the lack of response from users, Nokia displaced its experience in gaming to smartphones and first showcased its next-generation mobile gaming platform in 2006 (Soh \& Tan, 2008). This move is relevant not only for its technical performance but also as a starting point for the shift of market power in mobile gaming from carriers to handset suppliers and application providers.

However, it was the appearance of the iPhone (late 2007) that dramatically changed the circumstances of mobile gaming. The combination of new possibilities in the handset (touch screen, motion sensor, precise location system, enhanced display, heavy storage, high-quality audio, and embedded camera) and the ubiquitous connection to the network allowed many innovations, including application stores, playing on-line while on the move, multi-player games, playing across several media using social networks, games linked with device motion, and location-based gaming. ${ }^{4}$

The years 2007 and 2008 brought significant innovations in business models to the market. For instance, in the UK, the operators T-Mobile and Blyk began experimenting with advertising-supported games. Likewise, Greystripe and Glu Mobile, two popular providers of games, offered users free playing in exchange for exposure to advertising. There were also examples of blurring boundaries across media. For instance, a number of companies began to use Facebook to

\footnotetext{
${ }^{1}$ This occurred approximately three years earlier in Japan; see, for instance, Lindmark and Bohlin (2003).

2 Also referred to as on-deck games (content and applications, in general), in contrast to off-deck or off-portal games, located in third-party portals.

3 See the evolution in Feijoo and Gómez-Barroso (2009).

4 Arguably, Electronic Arts' Spore Origins, in early 2008, was the first big hit in mobile games to make use of some of these new possibilities. However, iTetris remained the most popular game in 2008 (PWC, 2009).
} 
distribute games to mobile players. Other popular games, like The Sims, provided additional game content to be downloaded to mobile phones. From 2007 on, a number of development studios decided to focus exclusively on mobile devices instead of porting existing console or PC games.

Since 2008, the model has become stable. Browsing from mobile devices and downloading from application stores are becoming the standard way to consume mobile games. Due to the diffusion of handsets and the increasing affordability of mobile data plans, the mobile platform reaches wider demographics than ever and offers ample space for the adaptation of existing games and the development of new types of games. Mobile devices are already a viable alternative to other gaming platforms. ${ }^{5}$

In addition to this broad market base, mobile games can make intensive use of the competitive advantages of the mobile platform, such as complete ubiquity (availability at any time and any place), the highest level of personalisation (while maintaining close contact with social networks), and, looking into the future, context awareness (with location as a current and main example). Therefore, the mobile gaming scenario is no longer that of a delayed or modest extension of console or PC games. Rather, mobile gaming is a distinct user experience with a number of unexplored avenues.

\section{Supply side of mobile gaming}

\subsection{Actors in the arena: the mobile ecosystem}

There are a number of different methodologies to explore the supply side of mobile content and applications. Among the most relevant approaches are the modelling of the business model in detail (Bouwman, Faber, Haaker, Kijl, \& Reuver, 2008), the inclusion of dynamics to improve the understanding of the evolution of business models (Eaton, ElalufCalderwood, \& Sorensen, 2010) and conceptualising the relationships to establish an e-business model (Osterwalder \& Pigneur, 2010). This article follows the ecosystem approach (Fransman, 2007), a more general theory that is nevertheless able to simultaneously capture the technical, economic and institutional relationships in an emergent domain that is not yet mature enough for proper modelling with more specialised methods. Therefore, this method is better suited to identify potential policy measures.

The general ecosystem of the mobile industry is introduced in Feijóo, Maghiros, Abadie, and Gómez-Barroso (2009). The adaptation for mobile gaming is presented in Fig. 1. As seen in the figure, the mobile gaming ecosystem follows the conventional three-stage model for digital mass consumption: (1) creation/production/publishing, (2) delivery/distribution/access and (3) use/consumption/interaction. The figure also highlights the activities in the software game industries that are independent of mobile games (white boxes), the elements that are directly connected to or necessary for mobile games (pale grey boxes) and the new - and generally non-existent - activities that may be required for next-generation mobile games (dark grey boxes).

In comparing the main players of the software games industry, it can be said that in the mobile domain, the market relevance of game publishers - the key player in other gaming platforms - is counterbalanced by the relevance of mobile operators, handset suppliers and application store providers. It is obvious from the number of activities required to develop and market a mobile game that the structure of the ecosystem is complex. From the perspectives of developers and publishers, putting a mobile game onto the market involves more steps than other gaming platforms. In a typical scenario, mobile games must match a quintuple layer of technical specifications: type of device, operating system in the device, applications in the device that could be connected with the game, features of the technologies used in the network infrastructure and implementations of support systems, including portals, application stores, platforms, business models or billing. In addition, there may be other specifications related to user profiles and/or contexts. In the mobile domain, the first three layers mentioned offer a multiplicity of possibilities not found in other gaming environments, such as video consoles or on-line games.

\subsection{Power struggle inside the ecosystem: mobile platforms}

Any successful mobile service provision requires the cooperation of different players in each of the stages shown. Therefore, integrating as many activities as possible or, at least, maintaining control of them is a rational step toward decreasing the transaction costs. This is the platformisation of the mobile ecosystem, in which the main players attempt to group together, in a loose or tight scheme, all of the required roles for a common set of hardware, software and other techno-economic specifications. Each of these platforms is seeking new revenues from the combination of mobile content and applications with their portfolio of products and services. Mobile games are included in these portfolios. Consequently, how platforms evolve is presently one of the key elements in understanding mobile gaming industry trends.

The current success of mobile platforms implies a clash of business models and cultures. Content and application providers intend the network to be neutral and a mere system of transport and distribution, whereas operators attempt to

\footnotetext{
${ }^{5}$ The Information Solutions Group (2011) shows the results of a survey from January 2011 with 2425 UK and US online panellists. When asked to identify which gaming-enabled device they played games on most often, $44 \%$ cited their phones, ahead of videogame consoles ( $21 \%$ ) and computers (30\%). Smartphone owners are by far the most avid mobile gamers: $93 \%$ of smartphone owners say they play at least once each week, and $45 \%$ play daily.
} 


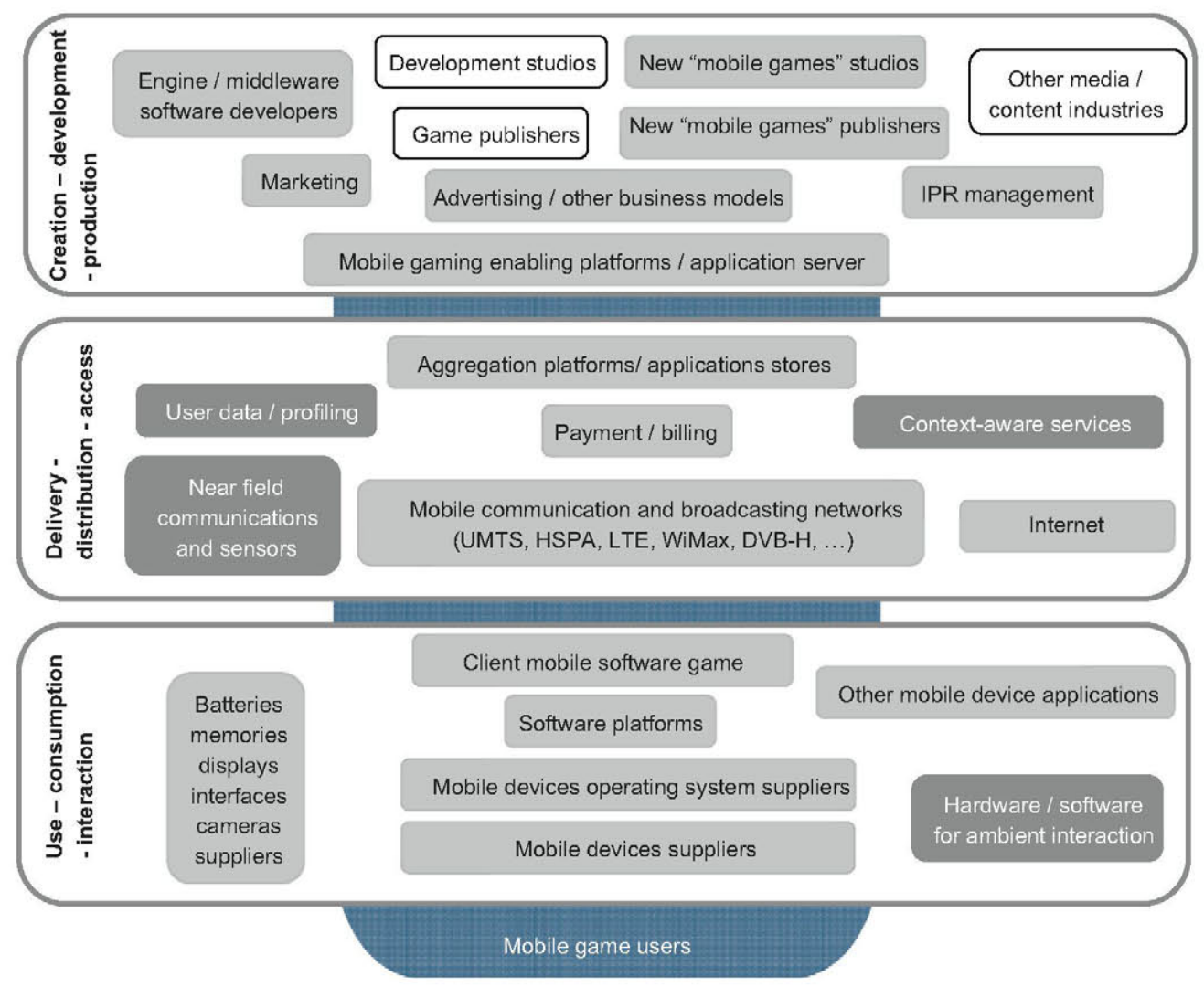

Fig. 1. Structure and main activities in the mobile games ecosystem.

complement connectivity with value-added content and applications. Furthermore, the hardware and software suppliers of mobile devices are looking into silo models to extend their control along the value chain. This partly latent conflict implies that the market is still in an early stage of competition for platform control. Thus, the platform owners now negotiate with mobile operators to ensure the subsidised presence of the device part of the platform in each of the national mobile communications markets. As part of this new platform scenario, the application stores seem to be the market shapers. They significantly influence users' perceptions of mobile content and applications, not just the innovations of application developers. ${ }^{6}$

Interestingly, each of the main platforms represents a different approach for developers and consumers. Apple's strategy suits the closed model rather strictly (Ballon, 2009); they use a proprietary software development kit on top of their own operating system and hardware and maintain tight control on the developments and features of the applications. On the opposite side of the coin, Google's strategy follows the open innovation model very closely (Chesbrough, 2006), in which available knowledge, both internal and external, is used to accelerate internal innovation and expand the market for the external use of innovation. This model is akin to open source software. However, Google retains the steering wheel for the evolution of the platform. In fact, Google subsidises the development of Android in exchange for determining the most appropriate roadmap for the software. Nokia's model has been meandering somewhere between the two, with the main difference of covering not only the smartphones segment but also the feature phones segment. ${ }^{7}$ Other main players in the mobile ecosystem have followed similar steps in their approach to building mobile platforms. For instance, Microsoft (Windows for Mobile), RIM (Blackberry), Palm, Samsung, Sony-Ericsson, Sun, Qualcomm, vendor independent platforms, the mobile operators themselves (Vodafone, Telefonica, etc.), and even Facebook have announced - and established - application stores and software platforms for interested developers.

All platforms have a relatively common structure. For instance, Apple's platform is composed of four main pieces: the iPhone-iPod-iPad as the mobile/portable devices (including Apple iOS as the operating system); the App Store, where applications are available for users to download; iTunes software, as the billing and control system; and a software development kit (SDK) for interested parties. The same model has been imitated by Google (the Android suite, the smartphones based on it, its application store, and a set of software facilities for developers) and Microsoft (Windows

\footnotetext{
${ }^{6}$ For a deeper analysis of the structure of mobile markets, see Holzer and Ondrus (2011), Lescop and Isckia (2010), or Said and Adham (2010).

${ }^{7}$ A model that is under review as of the Nokia and Microsoft alliance in 2011.
} 
Mobile, smartphones using this operating system, an application store and the corresponding software development kit, SDK). In the case of Nokia, the model was partly in place before the iPhone's introduction into the market and included its own handsets, the Symbian operating system for mobile devices and the Ovi services and application store. However, as of 2011, the Ovi store has been closed, and there are considerable uncertainties regarding the evolution of Symbian after the alliance between Nokia and Microsoft.

\subsection{Game developers in a universe of mobile platforms}

Initially, platforms followed the logic of the operators' walled garden: it was only possible to develop applications within the platform. However, the role of developers has changed dramatically from 2008 to 2011, and they have become the main engine in mobile software innovation. Suppliers, platforms and network operators are competing to build strong developer communities because their success is measured in terms of the number of applications and downloads.

Apple's App Store virtual storefront was launched in July 2008 in conjunction with the U.S. retail debut of the iPhone $3 \mathrm{G}$. At that time, developers could only create third-party iPhone applications that ran remotely via the Safari web browser installed in the device. However, the success of the iPhone and the availability of programs to bypass the software restrictions in the iOS probably caused the reaction from Apple and the availability, from March 2008, of an SDK that permits developers to produce sanctioned third-party applications for the iPhone. However, Apple reserves a high degree of control over every element of the platform and, particularly, over the approval of applications. ${ }^{8}$ Initially, games represented about a third of the available applications on Apple's app store. During 2010, approximately 2000 new games were added to the app store each month. The average price of the game category was $\$ 1.36$, and the average time for the approval of an application was 4 day (with a reported maximum of 38 day). ${ }^{9}$

Google launched its application store, Android Market, in October 2008, with corresponding processes for charging, billing and sharing revenues with developers and publishers. Google retains 30\% of the revenues of its app store to compensate for the expenses in steering and developing the Android software, the same amount as Apple. Following the open logic (and unlike Apple), in the Android Market, there is no mechanism for prior approval of applications in the store; their functionalities and contents are the responsibility of the developers and publishers. However, the main conditions for developers are relatively similar to Apple's conditions. ${ }^{10}$ The share of games among the applications in the store is similar to that of Apple's App Store.

From the perspective of developers, the strategy of Microsoft's Windows is a closed model, similar to that of Apple. However, Microsoft has introduced interoperability packages in its SDK, enabling mobile developers to port their iOS and Android applications to the Windows Phone mobile operating system.

The mobile browser as a platform must also be mentioned. Mobile application developers face the primary decision to programme in any of the so-called native platforms mentioned above or in web technology (Charland \& Leroux, 2011). Currently, the web stack has not achieved the level of performance that is possible with native code. However, considering the appeal of the Internet and mobile phones, it will come close in the next few years.

Examining mobile gaming in detail, from the perspective of developers, new platforms and application stores have had a considerable impact. While development and marketing costs for a console or PC game may run in the millions of euros, the costs for a mobile game are typically in the range of hundreds of thousands, and sometimes even less (Soh \& Tan, 2008), before the emergence of platforms. In the new platforms, these costs may be an order of magnitude lower. Thus, the low entry barriers for mobile games have helped spawn a proliferation of small mobile-game software developers and the possibility to account for the long tail of potentially interested gamers. However, the low costs of development in the new mobile platforms and the availability of a direct-to-consumer channel are counterbalanced by the relatively high number of platform options. Consequently, there is an increase in transaction costs for developers who wish to work across several platforms. ${ }^{11}$ Furthermore, the enhanced competition among games in any of these platforms gives more relevance to the role of marketing and advertising and shifts the market power from developers to publishers and platform owners. The implications for developers have been summarised by Holzer and Ondrus (2011) and include easier access to consumers, lower development and distribution costs, and higher customisation costs.

Regarding the location of mobile game developers, anecdotal evidence compiled by the authors shows that mobile gaming is truly a multinational domain, with companies from several countries providing content. The evidence also shows signs of consolidation, with some companies appearing consistently across the rankings (Electronic Arts and

\footnotetext{
${ }^{8}$ As an example, according to the Electronic Frontier Foundation (EFF, retrieved from http://www.eff.org/files/20100127_iphone_dev_agr.pdf), Apple can revoke the digital certificate of any of your applications at any time, as stated in the terms of the iPhone Developer Program License Agreement, a contract all developers must sign to distribute their software via the app store. In fact, until the end of 2009 , there was no adult content on the iPhone, and many applications suffered delays entering the app store.

${ }^{9}$ Retrieved from http://148apps.biz/app-store-metrics/ for the latest information on app store statistics.

${ }^{10}$ Google retains the right to remotely remove applications from the device, does not provide customer support for applications distributed on the Android Market, and it does not allow content that contains nudity, sexually explicit material, violent or bullying behaviour, hate speech, private and confidential information, malicious or prohibited products, illegal activities, or infringements of copyright.

${ }^{11}$ According to a survey of 850 developers in 75 countries (VisionMobile, 2011), $67 \%$ use Android, $59 \%$ use iOS, $56 \%$ use mobile web (that is, a mobile browser), $46 \%$ use Java ME, 45\% use Blackberry, 38\% use Symbian and 36\% use Windows Phone. Both Android and ios have grown $10 \%$ in comparison with the previous year. The same survey shows that the most significant driver in platform adoption for developers is, logically, market penetration.
} 
Gameloft are the main examples) and others being the target of acquisitions by entertainment-oriented players. At the same time, there are some small companies and even highly successful individual developers (Team17, Firemint or Lupis Labs are notorious examples in the Android platform), which supports the suggestion of low entry barriers. Also relevant to developers, a number of major players are crafting their own strategies in the domain (recent examples are Disney, Microsoft, Sony-Ericsson, and Apple). Most of these strategies include building an in-house development team for mobile gaming. This team can be developed from existing internal knowledge in the company and by hiring or acquiring external knowledge. If this situation becomes usual for mobile game development, the precedents in the console industry indicate that in-house developer teams will be favoured at the expense of publishing partners.

\subsection{Business models for mobile gaming}

There continues to be general ignorance about the most successful business models for mobile games. In general terms, it can be said that the traditional mobile industry focuses on generating revenue from mobile gaming (and many other applications) as an additional (and secondary) source with regard to voice and data. Alternatively, content-entertainment industries attempt to determine how to use the mobile channel as a supplementary source of revenue with regard to other gaming platforms. Finally, new platforms require business models that are suitable for flexible, application-centric configurations.

Game publishers (that is, content providers) translate the existing business models of the software game industry into the mobile domain: retailing (pay-as-you-go), premium retailing, the freemium model ${ }^{12}$ (the game with basic functionalities is free), and subscription (basically, for gaming on-line). For instance, according to Apple, games dominated the premium (that is, fee-based) iPhone applications in 2010, representing eight of the App Store's top ten bestsellers. ${ }^{13}$ However, games only represented four of the top ten free applications. ${ }^{14}$

Two more recent additions to business models in the domain are advergaming, the combination of advertising and gaming, and value-added applications, in which it is possible to access new functionalities during use that go beyond the traditional pay-per-download to incorporate billing within the application itself for additional content and services (Holden, 2009).

The business models for the other main types of players - operators, suppliers and application store owners - rely on their market power in the mobile ecosystem to arrive at some form of shared revenues with the game publisher or to benefit from their position in the ecosystem (billing or customer relationships, for instance).

\section{Demand side of mobile gaming: the user perspective}

\subsection{From potential to actual use}

The personalisation of mobile content and applications has long been considered the main differential attribute, together with ubiquity, of the mobile platform from the user perspective. However, empirical surveys show that the process of accepting advanced mobile services, particularly gaming, is more complex than simply providing these two attributes (a mere supply side approach). These studies also prove that a gap continues to exist between the intention to use and actual usage, and a more comprehensive demand side approach is still lacking.

This gap was anticipated by Verkasalo (2008), who used a panel of 579 active smartphone users in Finland to show that the short-term usage intention of gaming on a mobile was a meagre $21.7 \%$, whereas the practical usage was only $12.9 \%$. The explanation for these low results seems to lie in the combination of three factors: no value perceived (no need), pricing, and the existence of alternative devices. In the same country, Kolmonen (2008) confirmed what seemed obvious: flat-rate tariff pricing is a driver for diffusion, whereas low usability is a barrier, especially for small screen resolution. These are becoming issues of the past, at least in most parts of the developed world. However, in a more recent study of the Finnish market for three main applications, maps, games and mobile Internet, Verkasalo, López-Nicolás, Molina-Castillo and Bouwman (2009) conclude that people who own a smartphone do not automatically use all of the available services.

Other factors must be considered when examining the diffusion of mobile services in general and mobile gaming in particular. In the US, a survey of 1163 US respondents conducted in 2007 (Rice \& Katz, 2008) showed that demographics (such as digital divide factors and social support), privacy concerns, and prior communication technology use should also be included as factors to explain users' interest in new mobile services for entertainment. Social playability and acceptance have also been noted as key challenges in the design of pervasive mobile games (Ermi \& Mäyrä, 2005). A more recent study in the Netherlands of 542 users (Bouwman, López-Nicolás, \& Molina-Castillo, 2009) confirmed that lifestyles - that is, how people live, how they spend their money and how they allocate their time - have a decisive influence on the adoption of mobile entertainment solutions.

\footnotetext{
${ }^{12}$ In a survey by the Information Solutions Group (2011), 43\% of all mobile gamers and 49\% of smartphone gamers said they had upgraded a free trial game to the premium version during 2010 .

${ }^{13}$ Led by Angry Birds (from Finnish studio Rovio Movile), and followed, in descending order, by Doodle Jump, Skee-Ball, Bejeweled $2+$ Blitz, Fruit Ninja, Cut the Rope, Gamebox 1, and Plants vs. Zombies. All are priced at $\$ 0.99$, with the exception of Plants vs. Zombies, which is priced at $\$ 2.99$ per download.

${ }^{14}$ Angry Birds Lite (premium retailing), followed by Tap Tap Revenge 3 (premium retailing), Paper Toss (an example of premium retailing and advergaming at the same time), and Rock Band Free (premium retailing).
} 
As a major European-wide survey confirmed, trust, in particular, is a key aspect of personal relationships with mobile devices, which now belong to the intimate sphere of the user to a greater extent than any other device in the past (EuroBarometer, 2011). Knowledge of the contexts and situations of the use of the mobile is a major source of potentially appealing applications. However, it is unclear whether users are interested in the exchange of personal data for usefulness or for entertainment. In this respect, some unfortunate cases of consumer abuse have occurred. ${ }^{15}$

As another example of the dimensions of this issue, mechanisms for restricting mobile access to gambling or adult content are particularly inconsistent. A report by the US Federal Trade Commission (FTC, 2009) identified concerns over the availability of age-inappropriate content in mobile games, noting, for instance, that most mobile games are not rated according to the standards established by the Entertainment Software Rating Board (ESRB). The FTC study examined the websites of Apple, Verizon Wireless, AT\&T, Sprint and Nokia to assess their respective efforts to rate advertised mobile game titles. The FTC determined that all five websites offered games containing violent content, some of them mobile versions of home console titles tagged with the ESRB's M-for-mature rating. The FTC commends mobile game sellers for instituting rating systems for their products, but it adds that the proliferation of different systems could create consumer confusion. "Further, it is important that these alternative systems be credible and comprehensive," the report states (FTC, 2009, p. 29).

As a final remark, it should be noted that the mobile game consumer is not isolated from other daily activities and must divide the use of the device and the time for game playing with other main uses, such as communications (voice, SMS), Internet (web browsing, emailing, social networking, etc.), competing applications (music, video, etc.) and gaming on other platforms (video consoles, PC, etc.). Therefore, the demand cannot grow indefinitely, and going beyond the current levels of usage (and spending) would require substituting some of these other activities while providing added benefits. The progress in infrastructure and devices will help to push the frontier further. For example, tablets are worth considering separately as providers of a different gameplay experience from that of a smartphone. Indeed, Mobclix reports that gaming sessions on the iPad typically run three times longer than the same title on the iPhone. ${ }^{16}$

\subsection{Profile of the mobile gamer}

The first attribute of interest is the wide demographics of mobile gaming due to the enormous (and increasing) penetration of mobile devices. This can be considered an amplified version of the situation in which the initial use of video console games by early adopters led to broader age and income profiles. In addition, mobile games are much more ubiquitous than any other gaming platform. The Information Solutions Group (2011) revealed that more than one-third of all adults in the US and the UK played mobile games at least once per month, and $52 \%$ of all respondents had played a mobile game at some point in their lives. A relatively older but interesting survey of US consumers in the winter of 2007-2008 (Accenture, 2009) revealed that baby boomers (aged 45 and older) increased their video game playing via mobile devices by $52 \%$ compared with a modest increase of $2 \%$ for generation-Y consumers (aged 18-24), although obviously they began from much different levels of penetration.

Significant regional differences exist in the adoption of mobile gaming due to disparities in the availability and affordability of mobile infrastructures and terminals as well as lifestyles. Among the major world regions, Asia has led this market, with Japan and Korea in front. Because there are, and will continue to be, more mobile subscribers in Asia than in the rest of the world combined, Asia will maintain its lead for the foreseeable future, assisted by mobile communication technology upgrades. In addition, analysts (Holden, 2007) believe that the fastest growing region for mobile gaming will be the Indian subcontinent due to the fact that the mobile handset is the de facto games console in a region with negligible broadband penetration and no console base to speak of.

To know more about the mobile gamer profile, the authors conducted a simple survey of university students in Spain during the autumn of 2010. The overall findings displayed a rather passive attitude toward mobile gaming. In a random sample of 215 students (with only $13.1 \%$ of them using the mobile Internet and $14.3 \%$ owning a smartphone), $30.3 \%$ of the interviewees said that they used their mobile device for occasional gaming, and $12.8 \%$ had played mobile games only during the first days of owning a new device. Although a significant number of users (43.1\%) affirmed that they had played mobile games, they referred mostly to sporadic use of built-in games, and only a small group downloaded mobile games by side-loading from PC Internet access (7.6\%), by Bluetooth exchange (2.7\%) or by downloading from mobile content portals and app stores (3.4\%). Preferences in game genres were found to be fairly well distributed, with similar percentages for strategy (18.4\%), platforms (17.9\%), braintraining (22.8\%) and puzzles (30.4\%). A vast majority of informants $(71.9 \%)$ considered $€ 1-3$ an excessive price for a mobile game, and only $24.3 \%$ of the sample considered that amount to be reasonable. Accordingly, $61 \%$ said they would exclusively download free games.

\section{Challenges and disruptions to mobile gaming}

From the discussion in the two preceding sections on supply and demand, it can be concluded that the conditions necessary for the continuing growth of the mobile gaming industry are currently in place. However, a number of

\footnotetext{
${ }^{15}$ A 2008 EU-wide investigation into websites offering mobile phone services, such as ringtones and wallpapers, concluded that $80 \%$ of the sites required further investigation for suspected breaches of EU consumer rules (European Commission, 2008).

${ }^{16}$ Retrieved from http://www.fiercemobilecontent.com/special-reports/five-ipad-titles-are-revolutionizing-mobile-gaming.
} 
challenges remain for this growth to occur on a larger scale. Additionally, new developments and disruptions could modify the market situation.

To sum up, two factors particularly contribute to mobile gaming: first, broadband mobile data networks have become increasingly available and affordable, and second, usable and affordable smartphones and other smart devices are rapidly becoming the standard across many national markets. Furthermore, the mobile platform offers a number of features that are well suited to the massive adoption of gaming, including wide demographics, its status as the only truly interactive platform available in many developing countries, ubiquity (any time, any place), casual usage, the ability to be both personal and capable of maintaining close links with social networks, and its ability to supply content and applications adapted to the context of the user.

In the middle term, however, mobile gaming will confront the main challenges of increasing acceptance by users and overcoming the image of being a simple time filler. A main set of hurdles that must be overcome to increase adoption are those related to privacy, trust and consumer protection, as confirmed by surveys (EuroBarometer, 2011). These factors may not be different from the case of the Internet, but they may be more intense due to the personal nature of users' relationships with their mobile devices. ${ }^{17}$ The second main challenge is to develop solid business models. In addition to the traditional pay-as-you-go, online gaming subscription or premium versions, the possibilities of advertising, advergaming and other products and services purchased in, for or through the game are yet to be explored. In the particular case of location-based applications, Dhar and Varshney (2011) mention, in addition to the above, the need to address the challenges of acceptable standards for mobile advertising and performance guarantees.

A 2008 survey of 876 mobile industry experts (Netsize, 2009) seems to confirm the arguments in the previous paragraphs about a divide between the industry and the consumers. Mobile game publishers thought the key drivers for the industry were the porting of games across platforms, the building of communities around the game and the access to marketing and advertising tools, whereas the consumers felt that the key drivers were mobile data billing transparency, innovative business models that could balance users' interest in games and their price, and new types of games.

In particular, this last idea, new types of games, deserves to be explored in some detail when talking about disruptions. Two potential main disruptions emerge in the mobile content and applications domain: the cross media usage of social networks and the leverage of context.

Mobile multiplayer games are, in fact, an early version of a social network for gaming. Social networks add two additional possibilities to the gaming concept: building a community around the game (which could extend far beyond it) and viral distribution. The integration of the most popular Internet social networks, such as Facebook, into the mobile phone and the emergence of purely mobile social networks, such as Twitter, contribute to the combination of mobile gaming and social networks. ${ }^{18}$ In 2010 , cross-platform gaming based on social networks was announced. ${ }^{19}$ The Information Solutions Group (2011) indicates that 19\% of US and UK mobile gamers played one or more social networking games on their phones daily, and $37 \%$ of them played at least once a week.

With regard to the use of context in gaming, context characteristics are typically derived from sensors, both users' bioparameters and their physical environments, and from cognitive technologies (Klemettinen, 2007). The use of context is expected to reveal undiscovered needs and interactions (Dhar \& Varshney, 2011; Yndurain, Feijóo, Ramos, \& Campo, 2010). For instance, because mobile devices have rich sensing capabilities, they facilitate augmenting the real world commons with the Internet (Griswold, 2007). As an example of this potential, users leave traces that can be used either anonymously or with privacy matters resolved as a way of gaming. ${ }^{20}$ Mobile augmented reality (MAR), in which information from the virtual Internet world is superimposed on physical objects and browsed through a mobile device, is a concept that is usually associated with the use of context (Broll et al., 2008). The size of this market is negligible because only a minority of mobile phones are MAR-enabled. However, this proportion will rise dramatically in the medium term as a result of increasing adoption of smartphones and greater deployment of MAR enablers, such as digital compasses and accelerometers. ${ }^{21}$ Interestingly, location-based gaming is also a main concept behind the next generation of portable video consoles for gaming. ${ }^{22}$

\footnotetext{
${ }^{17}$ Although the behaviour of users is subject to a number of paradoxes such as the privacy paradox where people have a high perception of risk but disclose a range of personal information, or the control paradox where people desire full control of their personal data but avoid the hassle to keep it up to date (Lusoli, Maghiros, \& Bacigalupo, 2009).

${ }^{18}$ Available data (see Feijóo, Pascu, Misuraca, \& Lusoli, 2009) suggest that consumers do not wish to create new and separate social networking profiles for the mobile platform but instead prefer to access their existing social networking accounts on the go.

${ }^{19}$ In May 2010, RealNetworks launched GameHouse Fusion, a social gaming platform spanning multiple social websites and mobile devices. Zynga, a leading company in social gaming, introduced its first mobile social game, CityVille Hometown, in 2011. It enables gamers to create and build their own communities, inviting Facebook friends and in-game characters to become neighbours.

${ }^{20}$ For a detailed account of a location-based mobile game, see, for instance, De Souza d Silva (2008), in which Alien Revolt is described. The game used Java-enabled cell phones equipped with location awareness to transform the city into a battlefield. It also showed how limitations in available technologies at the time (the game was played with $2.5 \mathrm{G}-3 \mathrm{G}$ mobile communications) limited the diffusion of the game.

${ }^{21}$ Rovio announced in June 2011 the launch of Angry Birds Magic, a MAR-enabled extension of their Angry Birds game in which users interact with objects and other gamers via GPS and NFC technologies.

${ }^{22}$ For instance, in 2011, PlayStation Vita introduced Near, an application that pinpoints which titles other nearby Vita gamers are currently playing as well as the most popular titles in the area. Near also enables location-based gaming features, such as gifting (enabling users to access virtual gamerelated items that other gamers are sharing by checking in at geographic locations that others have previously visited). Following the MAR rationale, PlayStation Vita includes front and rear cameras, GPS, six-axis motion sensors and a three-axis electronic compass, and wireless connectivity.
} 


\section{Conclusions: is there a role for policy?}

The advent of the new socio-economic paradigm represented by the information society presents countries with risks and opportunities. The support for information technologies and service industries appears to be a sure path for future economic development-indeed, this may be the only way for countries with narrow domestic markets or limited physical resources to prosperity. This general remark is particularly true in times of crisis, when countries are desperately searching for ways to return the economy to its growth path.

In this scenario, mobile gaming is a non-negligible opportunity as it becomes an increasingly relevant industry. Thus, beyond mere techno-economics lie a number of policy options to assist the mobile gaming sector. In addition to being a promising activity, there are additional reasons to justify public support of mobile gaming. The rationales for potential policy intervention fall into three categories: (i) the positive consequences for employment and growth derived from attracting, rewarding and sustaining innovation in the mobile gaming field, (ii) the cultural and consumer aspects of software games, and (iii) the contributions from mobile gaming to the public provision of services, such as education, health and sustainability.

Beginning with innovation, the obvious general policy recipes include the following: regulatory and economic measures to foster the development of next-generation mobile networks, including spectrum management reforms; supporting research, development and innovation; consumer protection to increase trust (self-regulation, codes of conduct, labelling, information, user empowerment, avoiding scams, etc.); strengthening the institutional framework (venture capital, support to innovators, education on new technologies, etc.); content regulation (use of advertising, classification of content, etc.) and promoting standards. ${ }^{23}$

Each of these policies will have a significant impact on mobile gaming, even if they are not specifically aimed at this domain. Their particularisation with regard to mobile gaming would entail (a) the support of innovations for some technologies related to context-awareness, augmented reality and sensors, (b) the development of a possible regulatory framework for new types of services, such as location services, ${ }^{24}$ which are very relevant for new types of mobile gaming, (c) consumer protection in games, as this content category is in the forefront of development, ${ }^{25}$ and (d) renewed support of gaming developers and innovators, with new instruments that acknowledge their specific types of service innovation rather than the usual tools to assist pure research and development.

The cultural aspects of mobile gaming and its potential support in the provision of public goods allow a departure from the set of policies that are automatically applicable to ICT industries. These new policy options would be closely linked to serious games, ${ }^{26}$ which comprise, rather vaguely, all games with purposes complementary to entertainment, such as training skills or promoting given values or behaviours (Susi, Johannesson, \& Backlund, 2007). In spite of the many opportunities for so-called mobile edutainment (De Freitas \& Griffiths, 2008) and apart from a few exceptions in the health domain and some educational games for children (see Pollak et al., 2010), the landscape of mobile serious games is rather disappointing.

There will be many practical ways to support mobile games for cultural and educational purposes and to implement practical policies. These policies could range from public procurement of educational and cultural services to development and innovation policies focused on mobile edutainment. Interestingly, the argument for public administrations as smart and sophisticated buyers was stressed in a study on the status of the software industry in Europe (Leimbach \& Friedewald, 2010). The same argument can be used in support of mobile games in other areas of public interest, such as health (or, better, wellness), awareness of energy efficiency and sustainability, civic responsibility, citizens' participation, and social creativity. The bottom line for supporting these different public initiatives would be to send a signal to all interested parties to begin thinking about mobile games as a tool with great potential for new social and educational initiatives.

\section{Acknowledgement}

This work partially draws from a Institute for Prospective Technologies Studies (IPTS) report on assessing the future competitiveness of the EU software videogame industry (De Prato, et al., 2010). It also draws from the Mobile Media Project (CSO2009-07108) supported by the Spanish Ministry of Science and Innovation.

\footnotetext{
${ }^{23}$ In the particular case of the EU, the harmonisation of the internal market (mobile data roaming, purchase of goods across Member States borders, levelled regulation for new services, etc.) should also be considered. The failure of the EU to produce mobile services innovation has been noted (Weber, Haas, \& Scuka, 2011).

${ }^{24}$ During 2011, it was reported that Apple's iPhone and iPod devices had recorded location and time-stamp data since the mid-2010 release of the iOS 4 software update, effectively creating a comprehensive log of all user movement and activities during that time. Google's Android behaved in a similar way. Several legislative initiatives are being established as of 2011 to increase users' control of their data and level of privacy.

${ }^{25}$ The issues regarding the classification of mobile games (adult, violence, hate, etc.) were discussed at the end of Section 4 . However, consumer protection would go beyond categorisation to include in-app purchases, scams, etc.

${ }^{26}$ A serious game is "a mental contest, played with a computer in accordance with specific rules that uses entertainment to further government or corporate training, education, health, public policy, and strategic communication objectives" (Zyda, 2005, p. 26). They originated in the late 1990s on the Internet (Amri, 2010). Powered by the development of social networks, serious games are a usual communication strategy in the Web's shop windows of diverse organisations: governments, political parties, NGOs, health, etc. Serious games also serve as donation channels for specific causes. However, serious games have repeatedly failed to enter the big games market.
} 


\section{References}

Accenture. (2009). Accenture consumer electronic usage survey. Retrieved from 〈http://www.accenture.com/Global/Research_and_Insights/By_Industry/ Electronics_and_High_Tech/USFindings.htm >.

Amri, Y. (2010). A conceptual framework for serious games and its validation. UK: University of Southampton Retrieved from 〈http://eprints.ecs.soton.ac. uk/21684/1/Thesis_017b.pdf $>$.

Ballon, P. (2009). The platformisation of the European mobile industry. Communications \& Strategies, 75, 15-34.

Bouwman, H., Faber, E., Haaker, T., Kijl, B., \& Reuver, M. D. (2008). Conceptualizing the STOF model. In: H. Bouwman, H. de Vos, \& T. Haaker (Eds.), Mobile service innovation and business models (pp. 31-70). Berlin: Springer Verlag.

Bouwman, H., López-Nicolás, C., \& Molina-Castillo, F. (2009). Consumer lifestyles and the adoption of value added mobile services. In Proceedings of the paper presented at the 8 th global mobility roundtable (GMR 2009), Cairo.

Broll, W., Lindt, I., Herbst, I., Ohlenburg, J., Braun, A. K., \& Wetzel, R. (2008). Toward next-gen mobile AR games. Computer Graphics and Applications, IEEE, $28(4), 40-48$.

Charland, A., \& Leroux, B. (2011). Mobile application development: Web vs. native. Communications of the ACM, 54(5), 49-53.

Chesbrough, H. (2006). Open innovation: A new paradigm for understanding industrial innovation. In: H. Chesbrough, W. Vanhaverbeke, \& J. West (Eds.), Open innovation. Researching a new paradigm (pp. 1-12). Oxford: Oxford University Press.

De Freitas, S., \& Griffiths, M. (2008). The convergence of gaming practices with other media forms: What potential for learning? A review of the literature. Learning, Media \& Technology, 33(1), 11-20.

De Souza e Silva, A. (2008). Alien revolt (2005-2007): A case study of the first location-based mobile game in Brazil. IEEE Technology and Society Magazine, $27(1), 18-28$.

Dhar, S., \& Varshney, U. (2011). Challenges and business models for mobile location-based services and advertising. Communications of the ACM, 54(5), 121-128.

Eaton, B., Elaluf-Calderwood, S., \& Sorensen, C. (2010). A methodology for analysing business model dynamics for mobile services using control points and triggers. In Proceedings of the paper presented at the 14th international conference on intelligence in next generation networks (ICIN), Berlin, Germany.

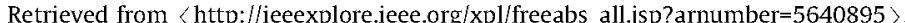

Ermi, L. \& Mäyrä, F. (2005). Challenges for pervasive mobile game design: Examining players' emotional responses. In Proceedings of the 2005 ACM SIGCHI

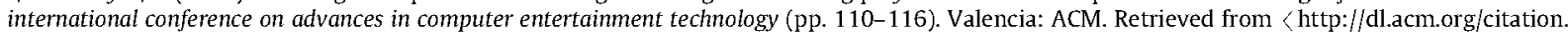
cfm?id=1178554>.

EuroBarometer, U. (2011). Special Eurobarometer 359. Attitudes on data protection and electronic identity in the European Union. Brussels, Belgium: European Commission Retrieved from 〈http://ec.europa.eu/public_opinion/archives/ebs/ebs_359_en.pdf 〉.

European Commission. (2008). EU crackdown of ringtone scams. Frequently asked questions. Retrieved from 〈http://europa.eu/rapid/pressReleasesAction. do? reference $=$ MEMO/08/516\& format $=$ HTML\&aged $=0$ \&language $=$ EN\&guiLanguage $=e n ~>$.

Feijóo, C., \& Gómez-Barroso, J. L. (2009). Factores clave en el acceso móvil a contenidos. El Profesional de la Información, 18(2), 145-154.

Feijóo, C., Maghiros, I., Abadie, F., \& Gómez-Barroso, J. L. (2009). Exploring a heterogeneous and fragmented digital ecosystem: Mobile content. Telematics $\mathcal{E}$ Informatics, 26(3), 282-292.

Feijóo, C., Pascu, C., Misuraca, G., \& Lusoli, W. (2009). The next paradigm shift in the mobile ecosystem: Mobile social computing and the increasing relevance of users. Communications \&' Strategies, $75,57-78$.

Fransman, M. (2007). The new ICT ecosystem. Implications for Europe. Edinburgh: Kokoro.

FTC, M. (2009). Marketing violent entertainment to children: A sixth follow-up review of industry practices in the motion picture, music recording 8 electronic game industries (A report to Congress). Washington: Federal Trade Commission Retrieved from 〈http://www.ftc.gov/os/2009/12/P994511 violenten tertainment.pdf $>$.

Goggin, G., \& Spurgeon, C. (2007). Premium rate culture: The new business of mobile interactivity. New Media E Society, 9(5), 753-770.

Griswold, W. G. (2007). Five enablers for mobile 2.0. Computer, $40(10), 96-98$.

Holden, W. (2007). Mobile content for the masses. London: Juniper Research.

Holden, W. (2009). Mobile apps-taking a bit of the apple. London: Juniper Research.

Holzer, A., \& Ondrus, J. (2011). Mobile application market: A developer's perspective. Telematics and Informatics, 28(1), 22-31.

Information Solutions Group. (2011).2011 PopCap games mobile phone game research. Retrieved from 〈http://www.infosolutionsgroup.com/2011_Pop Cap_Mobile_Phone_Games_Presentation.pdf $>$.

Klemettinen, M. (Ed.). (2007). Chichester, England: John Wiley \& Sons.

Kolmonen, L. (2008). Mobile search engine survey. In Proceedings of the paper presented at the research seminaron telecommunications business. Retrieved from 〈http://www.tml.tkk.fi/Opinnot/T-109.7510/2008/Eng1.pdf 〉.

Leimbach, T., \& Friedewald, M. (2010). Assessing national policies to support software and software based services in Europe. Info, 12(6), 40-55.

Lescop, D., \& Isckia, T. (2010). (Re)shaping the mobile sector: The breaker, the Trojan and ... the shopping malls. Communications $\&$ Strategies, 78 , $161-169$.

Lindmark, S., \& Bohlin, E. (2003). The i-mode success story-Towards a system explanation. Communications \& Strategies, 52, 193-213.

Lusoli, W., Maghiros, I., \& Bacigalupo, M. (2009). eID policy in a turbulent environment: Is there a need for a new regulatory framework? Identity in the Information Society, 1(1), 173-187.

Netsize. (2009). The Netsize guide. Mobile society \& me: When worlds combine. Cologne. Retrieved from 〈http://www.netsize.com/Netsize-Guide-2009.htm 〉.

Osterwalder, A., \& Pigneur, Y. (2010). Business model generation. A handbook for visionaries, game changers, and challengers. Hoboken: John Wiley \& Sons.

Pollak, J., Gay, G., Byrne, S., Wagner, E., Retelny, D., \& Humphreys, L. (2010). It's time to eat! Using mobile games to promote healthy eating. Pervasive Computing, IEEE, 9(3), 21-27.

PWC, L. (2009). Global entertainment media outlook 2009-2013 ((10th Edition). New York: PriceWatehouseCoopers Retrieved from<http://kc3.pwc.es/ local/es/kc3/publicaciones.nsf/V1/2B603E27B45C2350C1257657002F250B/SFILE/informe\%20GEMO\%202009-2013\%20(definitivo).pdf >.

Rice, R. E., \& Katz, J. E. (2008). Assessing new cell phone text and video services. Telecommunications Policy, 32(7), 455-467.

Said, M. F., \& Adham, K. A. (2010). Online mobile content innovations and industry structure: Implications for firms' strategies. International Journal of Economics and Management, 4(1), 101-119.

Soh, J., \& Tan, B. (2008). Mobile gaming. Communications of the ACM, 51(3), 35-39.

Susi, T., Johannesson, M., \& Backlund, P. (2007). Serious games - An overview. Work paper No. HS-IKI-TR-07-001. School of Humanities and Informatics, University of Skövde, Sweden. Retrieved from 〈http://www.autzones.com/din6000/textes/semaine12/SusiEtAl(2005).pdf $\rangle$.

Verkasalo, H. (2008). From intentions to active usage: A study on mobile services in Finland. In Proceedings of the paper presented at the 19th European regional conference of the international telecommunications society, Rome, Italy.

Verkasalo, H., López-Nicolás, C., Molina-Castillo, F., \& Bouwman, H. (2009). Analysis of mobile Internet, map application and game adoption among smartphone users. In Proceedings of the paper presented at the 8th Global mobility roundtable (GMR 2009), Cairo, Egypt.

VisionMobile. (2011). Developers economics. How developers and brands are making money in the mobile app economy, London. Retreived from $\langle$ http://www.visionmobile.com/rsc/researchreports/VisionMobile-Developer_Economics_2011.pdf $\rangle$.

Weber, A., Haas, M., \& Scuka, D. (2011). Mobile service innovation: A European failure. Telecommun. Policy, 35(5), 469-480.

Yndurain, E., Feijôo, C., Ramos, S., \& Campo, C. (2010). Context-aware mobile applications design: Implications and challenges for a new industry. The Journal of the International Telecommunications Professional, 4(4), 209-227.

Zyda, M. (2005). From visual simulation to virtual reality to games. Computer, 38(9), 25-32. 